\title{
AC 2010-2187: INTRODUCING DATAFLOW PROGRAMMING IN A FRESHMAN ENGINEERING COURSE WITH APPLICATIONS IN SUSTAINABILITY EDUCATION
}

\section{Parhum Delgoshaei, Virginia Tech}

PARHUM DELGOSHAEI is a Ph.D. student in Engineering Education at Virginia Tech. He holds an M.S. in Electrical Engineering from Western Michigan University. His $\mathrm{PhD}$ research involves developing real-time remote monitoring systems and their application in enhancing sustainability education.

\section{Vinod Lohani, Virginia Tech}

Vinod K Lohani is an associate professor in the Engineering Education Department and an adjunct faculty in the Civil and Environmental Engineering at Virginia Tech. He received a PhD in civil engineering from Virginia Tech in 1995. His research interests are in the areas of knowledge modeling, water and energy sustainability, engineering learning modules for freshmen, and international collaboration. He leads a major curriculum reform project (2004-09), funded under the department-level reform program of the NSF, at Virginia Tech. A spiral curriculum approach is adopted to reformulate engineering curriculum in bioprocess engineering in this project. He co-authored an award winning paper with his $\mathrm{PhD}$ student at the 2007 annual conference of ASEE. He received the College of Engineering Faculty Fellow award in 2008.

\section{Chelsea Green, Virginia Tech}

Chelsea Green is a graduate student in the Department of Civil and Environmental Engineering at Virginia Tech. She worked with LEWAS project investigators as an undergraduate researcher in fall '08 and spring '09 and as a graduate student in fall '09 and spring '10. 


\title{
Introducing Dataflow Programming in a Freshman Engineering Course with Applications in Sustainability Education
}

\begin{abstract}
This paper discusses the gradual integration of LabVIEW, a dataflow programming language, into a freshman engineering course, data acquisition activities designed to utilize LabVIEW programming and the status of development of a LabVIEW Enabled Watershed Assessment System (LEWAS). This system is capable of monitoring water data in a real-time from an impaired stream that flows through the campus of Virginia Tech. These data have potential to develop classroom exercises targeted at promoting awareness of environmental sustainability among engineering freshmen.
\end{abstract}

LEWAS has been successfully expanded from the desktop version and is programmed to enable real-time monitoring using an embedded computer that is field deployable with less power consumption and more reliability compared to the desktop version. Student attitudinal responses on using LabVIEW to teach programming constructs and collect environmental data are analyzed and discussed.

\section{Introduction}

In 2004, a group of engineering and education faculty at Virginia Tech received a major curriculum reform and engineering education research grant under the department-level reform (DLR) program of the $\mathrm{NSF}^{1}$. A number of hands-on activities were developed and implemented in the freshman engineering program as a result of the DLR project ${ }^{2,3,4}$. Engineering Exploration (EngE1024), a freshman engineering course required of all engineering undergraduates, is the most affected course by the DLR project in the general engineering (also called freshman engineering) program. This course primarily focuses on hands-on design, problem solving, professional ethics and skills, and critical thinking skills ${ }^{5}$. This course is taken by approximately 1700 freshmen every year. It is comprised of lecture and workshop sessions. One of the learning objectives of this course is that after successful completion the students should be able to develop and implement algorithms and demonstrate understanding of basic programming concepts. The instructors used FORTRAN in late 90s which was replaced byMATLAB in the beginning of this decade. Beginning in Fall '04, MATLAB was replaced by Alice programming language. The authors have discussed their programming experiences with Alice in ${ }^{6}$. In Spring '07, Alice was replaced by LabVIEW programming. The dataflow programming paradigm supported by LabVIEW is suitable for many engineering applications and can be extended for collection, processing and communication of environmental data which in turn can be used to 
teach sustainability concepts ${ }^{6}$. The proposed LabVIEW Enabled Watershed Assessment System (LEWAS) is an attempt in this direction.

The rest of the paper is organized as follows. First, we briefly review the programming activities in EngE1024 prior to LabVIEW. Then, we discuss the gradual integration of LabVIEW and its applications into the course. This is followed by the discussion of current status of development of LEWAS. Analysis of assessment data from LabVIEW instruction modules is presented next. Finally, we discuss our future plans that facilitate learning about energy and environmental sustainability.

\section{Programming approaches used in EngE1024}

Prior to introduction of LabVIEW in EngE1024, two other programming languages were used in the course in this decade: MATLAB and Alice. MATLAB was used prior to Fall' '04 in the course to introduce students with basic programming skills. MATLAB was replaced with Alice (www.Alice.org) in Fall '04. The motivation to replace MATLAB is discussed in ${ }^{6}$. Alice teaches computer programming using an object-oriented approach in a 3D environment. Threedimensional "objects" are dragged and dropped and the program generates corresponding syntax which is editable. Students can enable interaction between these objects and acquire/change their properties by applying "methods" or "functions". Based on assessment data collected on Alice, it was determined that engineering freshmen, particularly with prior programming experiments (about $50 \%$ of freshmen in our program), did not appreciate the drag and drop programming approach adopted in Alice for learning fundamentals of object- oriented programming. Furthermore, students did not perceive direct engineering applications of Alice in future engineering courses. Hence, Alice was replaced with LabVIEW beginning in 2007 in the course

\section{LabVIEW Programming}

LabVIEW (Laboratory Virtual Instrumentation Engineering Workbench) is a visual programming language from the National Instruments. This software uses a dataflow programming model in which the output of each computation node is calculated when all the inputs are determined for that node. The calculations take place concurrently for nodes that do not have a data dependency. LabVIEW has been used in engineering courses for covering fundamental programming concepts ${ }^{6}$. In Fall '07 LabVIEW was introduced in the entire freshman engineering class (EngE1024). In fact, LabVIEW was introduced in Spring '07 but due to the tragic events at Virginia Tech, the LabVIEW curriculum was not completely implemented. LabVIEW is used in industry for data acquisition, processing signals and controlling instruments ${ }^{7}$. A graduate integration approach was adopted for bringing LabVIEW programming experiences into EngE1024 (see Table 1).

Table 1: LabVIEW Concepts/Applications in EngE1024 


\begin{tabular}{|c|c|c|}
\hline \begin{tabular}{|l} 
Core Concept \\
\end{tabular} & \begin{tabular}{|l} 
LabVIEW(LV) topic covered \\
\end{tabular} & Activity/Homework \\
\hline$\overline{\mathbf{A}}$ & $\begin{array}{l}\text { Introduction to LV programming } \\
\text { environment, VIs }\end{array}$ & $\begin{array}{l}\text { Watching LabVIEW video that } \\
\text { introduces the programming } \\
\text { environment and dataflow programming } \\
\text { using a small program. } \\
\text { Completing LabVIEW tutorial (finding } \\
\text { the roots a quadratic equation) }\end{array}$ \\
\hline B & $\begin{array}{l}\text { Controls and Indicators, Data } \\
\text { types } \\
\text { Observing dataflow by execution } \\
\text { highlighting }\end{array}$ & $\begin{array}{l}\text { Calculating grade from grade } \\
\text { components }\end{array}$ \\
\hline $\bar{C}$ & $\begin{array}{l}\text { Overview of Control Structures } \\
\text { in LV: Repetition Structures and } \\
\text { decision structures }\end{array}$ & $\begin{array}{l}\text { Calculating profit of a company } \\
\text { manufacturing x units based on unit } \\
\text { baseline price, price decrease per sold } \\
\text { unit, fixed costs and variable costs } \\
\text { (figure 1), introduced in Fall } 2009 \\
\end{array}$ \\
\hline$\overline{\mathrm{D}, \mathrm{E}}$ & $\begin{array}{l}\text { D: Repetition Structures in LV: } \\
\text { For loop } \\
\text { E: Boolean variables in LV }\end{array}$ & $\begin{array}{l}\text { Controlling a two wheel robot when } \\
\text { road boundaries were sensed }\end{array}$ \\
\hline$\overline{\mathbf{N}}$ & $\begin{array}{l}\text { Repetition Structures in LV: } \\
\text { While Loop }\end{array}$ & $\begin{array}{l}\text { Nanotechnology activity: develop VI for } \\
\text { Plotting normalized nanoscale potential } \\
\text { and use provided VI to measure the } \\
\text { surface to volume ratio of carbon } \\
\text { nanotubes }\end{array}$ \\
\hline $\mathbf{F}$ & $\begin{array}{l}\text { Decision Structures in LV: Case } \\
\text { structure }\end{array}$ & $\begin{array}{l}\text { Use case structure to calculate letter } \\
\text { grade from numerical grade }\end{array}$ \\
\hline$\overline{\mathbf{G}}$ & Introduction to data acquisition & $\begin{array}{l}\text { Data Acquisition Activity: collecting } \\
\text { and analyzing data (using exponential, } \\
\text { linear and power regression) from three } \\
\text { sensors (temperature, force and motion). } \\
\text { Detailed analysis of collected data from } \\
\text { temperature sensor and derivation of the } \\
\text { analytical function it represents } \\
\text { (Newton's Law of Cooling) in Fall } \\
\text { 2009: } \\
\text { Demonstration of data collection in } \\
\text { lecture sessions, derivation of function } \\
\text { in workshop session }\end{array}$ \\
\hline H & $\begin{array}{l}\text { Publishing a Virtual Instrument } \\
\text { over the Internet, acquiring real } \\
\text { time water quality data }\end{array}$ & $\begin{array}{l}\text { Remote Data Acquisition Activity: } \\
\text { collecting water quality data from server } \\
\text { computer connected to multi-probe } \\
\text { sonde }\end{array}$ \\
\hline
\end{tabular}




\begin{tabular}{|c|c|c|}
\hline I & $\begin{array}{l}\text { Remote access to a VI running } \\
\text { on an embedded computer with } \\
\text { wireless and storage modules } \\
\text { (LEWAS phase 2) to collect } \\
\text { water quality parameters of water } \\
\text { sample located in an indoor Lab }\end{array}$ & $\begin{array}{l}\text { Remote access demonstrated in lecture } \\
\text { sessions along with Skype video call to } \\
\text { lab computer }\end{array}$ \\
\hline 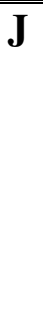 & $\begin{array}{l}\text { Remote access to a VI running } \\
\text { on an embedded computer with } \\
\text { wireless and storage modules } \\
\text { (LEWAS phase 3) to collect } \\
\text { water quality parameters of an } \\
\text { impaired creek located on } \\
\text { campus }\end{array}$ & $\begin{array}{l}\text { Planned for access from lecture session } \\
\text { in Spring } 2010 . \text { The VI is functionally } \\
\text { equivalent to the one discussed in }{ }^{10} \text {, } \\
\text { modified for LabVIEW Real-Time and } \\
\text { LabVIEW FPGA platforms }\end{array}$ \\
\hline
\end{tabular}

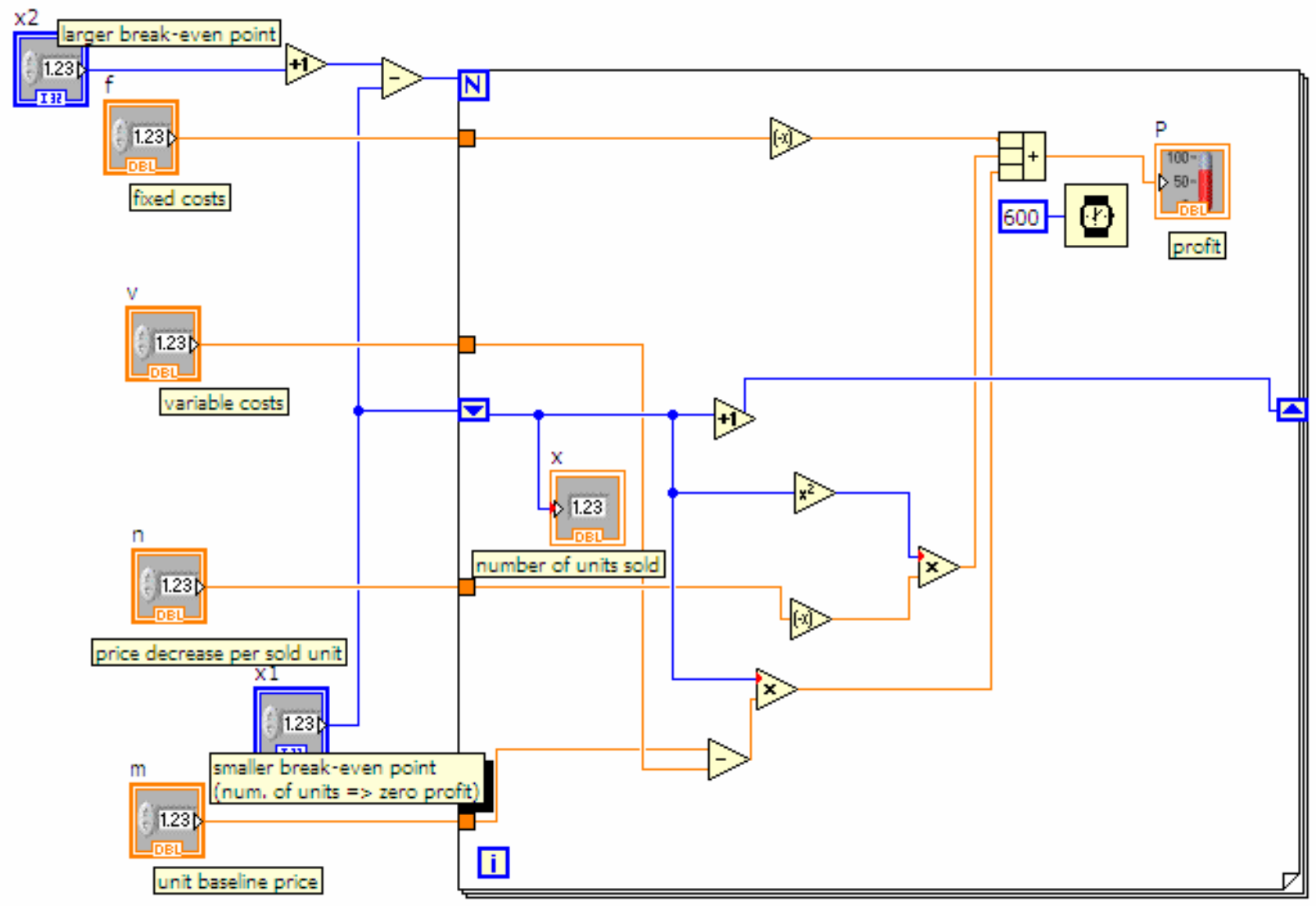

Figure 1. LabVIEW block diagram for demonstrating profit variation using a For loop when the "number of units sold" iterates between the two break-even (zero profit) points 
As shown in table 1, a logical process informed by students' feedback is followed to introduce new LabVIEW concepts into the course.

\section{LabVIEW activities in EngE1024 in Spring '09 and Fall '09}

In addition to learning basic programming concepts including various control structures, students participated in various hands-on LabVIEW learning modules designed to: (i) control the motion of a 2 -wheel robot $^{14}$, (ii) collect and analyze temperature data to validate Newton's law of cooling, (iii) demonstrate the real-time remote water quality monitoring capability of the LEWAS.

In the temperature data activity, a probe is first heated and then submerged into a container with water (see figure 4)for cooling. The probe is attached to a DAQ device that monitors the change in temperature of probe. This is done by measuring the voltage across a thermistor (a resistor whose resistance varies with temperature). The process of data acquisition which takes place in the SensorDAQ module consists of filtering the analog voltage signal from noise, amplifying it, sampling it at short intervals and quantizing these samples in the form of binary numbers sent to LabVIEW via the digital signal on the USB cable.

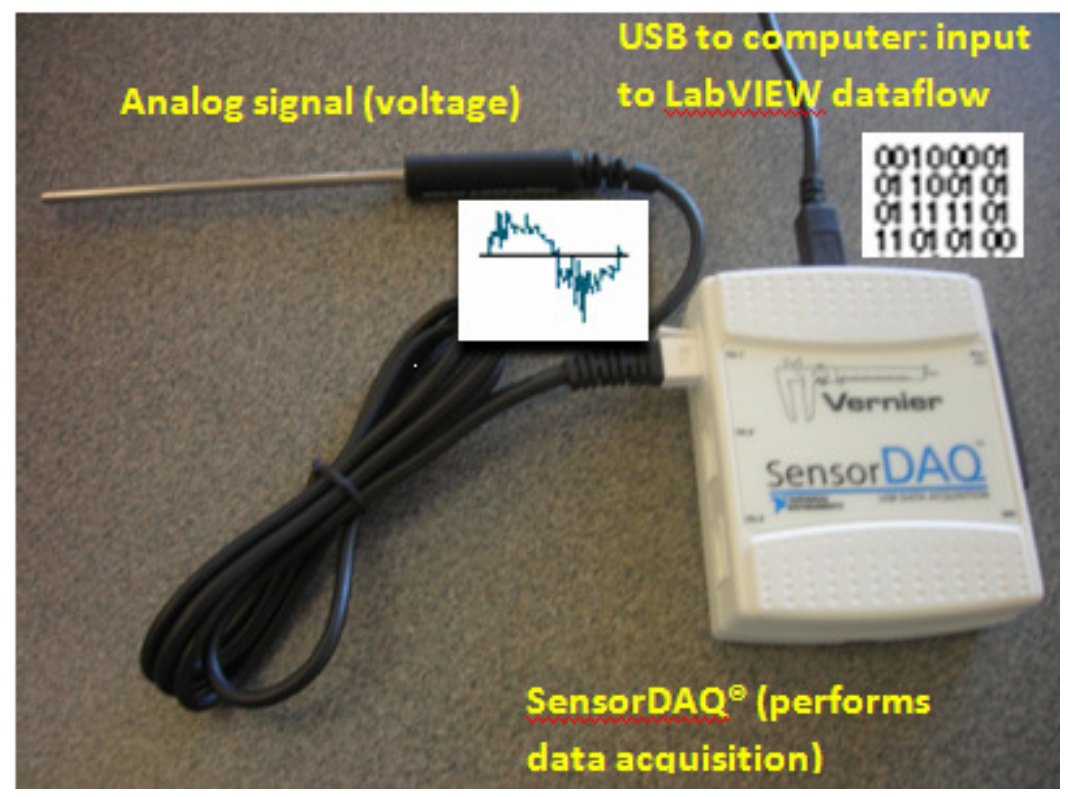

Figure 4: setup for the cooling probe experiment 
Students were provided with the LabVIEW VI that extracted and plotted the temperature data. The shaded area in figure 5 demonstrates the temperature falling regime of the probe when it was submerged in water after it was heated up. Newton's Law of Cooling states that the rate of change of the temperature of an object is proportional to the difference between its own temperature and the ambient temperature. This statement can be formulated into a differential equation. Equation (1) shows the solution of this differential equation.

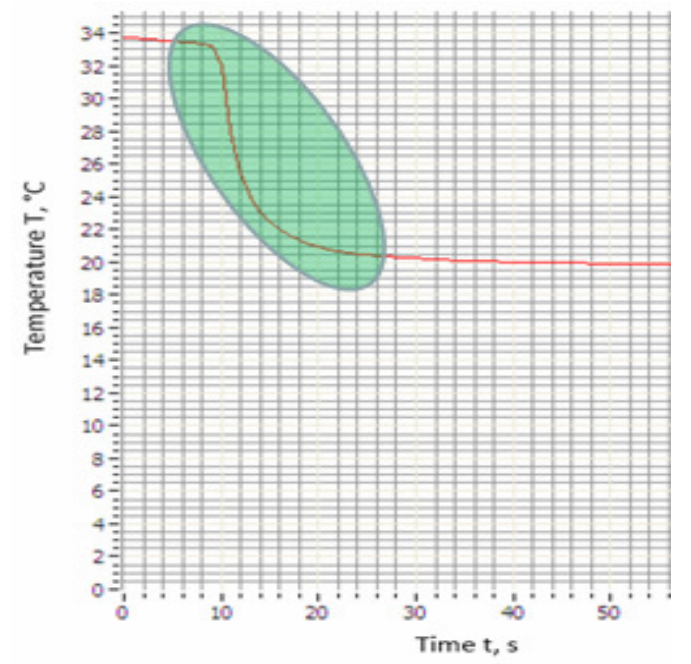

$$
T(t)=T_{a}+\left(T_{0}-T_{a}\right) e^{-k\left(t-t_{0}\right)}
$$

$T_{a}$ : ambient temperature

$T_{0}$ : initial temperature

$t_{0}:$ cooling start time

$k$ : decay constant

Figure 5: Newton's law of cooling (equation 1, right) and LabVIEW plot (left) based on empirical data collected in the setup depicted in figure 4

Students in EngE1024 are introduced to basic types of empirical functions (linear, power and exponential) and they learn the method of selected points and the least squares regression to fit these functions. Students used the temperature probe data (see shaded part in figure 5) to fit the best empirical function to related temperature with time and then compare their results with the Newton's law of cooling. This comparison validated the law and demonstrated the real life application of data acquisition of the LabVIEW. Introducing environmental sustainability in EngE1024The module focuses on water quality monitoring and its application in environmental sustainability and uses acreek (i.e., Stroubles creek) that is impaired (unable to support designated uses) on Virginia Tech's campus. Detailed information regarding the factors contributing to the impairment of the creekcan be found in ${ }^{8}$. Monitoring an impaired creekprovides the stakeholders with required data to determine the effectiveness of the best management practices (BMPs) employed to improve the water quality. ${ }^{9}$. Our purpose in this exercise was to emphasize the data acquisition, processing, and transmission capabilities of the LabVIEW. Since water quality in the creek is directly impacted by the activities in its watershed, we developed a short worksheet and called it " "Know your Watershed" worksheet. This worksheet introduced students to the concept of a watershed and Virginia Tech's own watershed. They were also asked to independently research the path a drop of water follows as it travels from Virginia Tech campus to the Gulf of Mexico. This worksheet also introduced students to current field monitoring techniques and important water quality parameters. In order 
to review the empirical function fitting concepts, the students were given actual data on dissolved oxygen (an indicator of stream health) and temperature values in a body of water (both parameters taken from the EPA website). And were asked to fit empirical functions that best represent these data. In addition, the "Know your Watershed" worksheet included relevant information and references s to explore the EPA website to learn more about impaired streams and watersheds.

\section{LabVIEW Enabled Watershed Assessment System (LEWAS)}

The LabVIEW Enabled Watershed Assessment System (LEWAS) is developed to enhance the sustainability component of EngE1024. This system has the capability to access water quality and quantity data in a real-time from an on-campus stream. The advantages of using a real-time remote monitoring system over traditional sampling is discussed in ${ }^{10}$. Furthermore, using realtime monitoring technology is becoming increasingly important for evaluating water quality ${ }^{11}$. From a broader perspective, using an on-campus creek as an educational site for water quality monitoring to demonstate environmental sustainability is significant due to three reasons ${ }^{12}$ : First, it makes students aware of what's happening or will happen in their own campus if watershed activities are not planned in a logical manner. Second, it enables us or a stakeholder to assess the efficiency of actions or regulation compliance. Third, it enables them to know the realworld application of the skills they acquire in various learning activities.

The development and implementation of LEWAS has been planned in three phases. The first phase which was implemented in an engineering lab in summer 2008, water quality data was collected using a multi-probe sonde and sent to LabVIEW which was loaded on the server computer (Tablet PC). The sonde had capability to sense temperature, conductivity, dissolved oxygen, and $\mathrm{pH}$ of water. These parameters are important indicators of water quality ${ }^{9}$. The data was shared with a remote client via Wireless LAN. Clients can control the VI running on the server remotely and receive water quality data ${ }^{10}$. A sample reading of data by the server computer which was also received by the client computers is shown in Figure 6. Figure 7 displays the LabVIEW VI developed for extracting water quality data. 


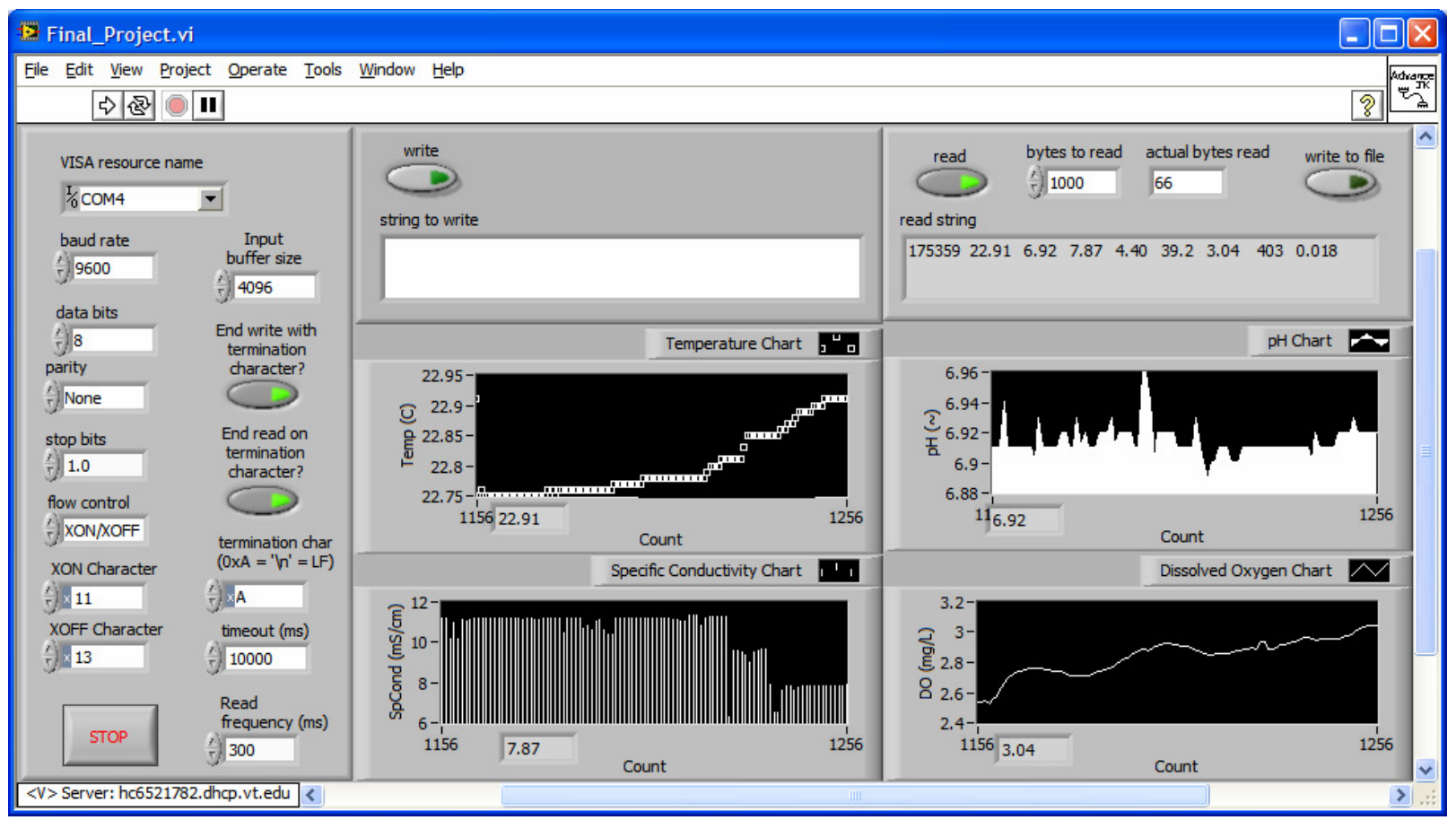

Figure 6: front panel for LEWAS phase 1 VI showing data that was read in while multi-probe sonde was attached in the Laboratory ${ }^{10}$.

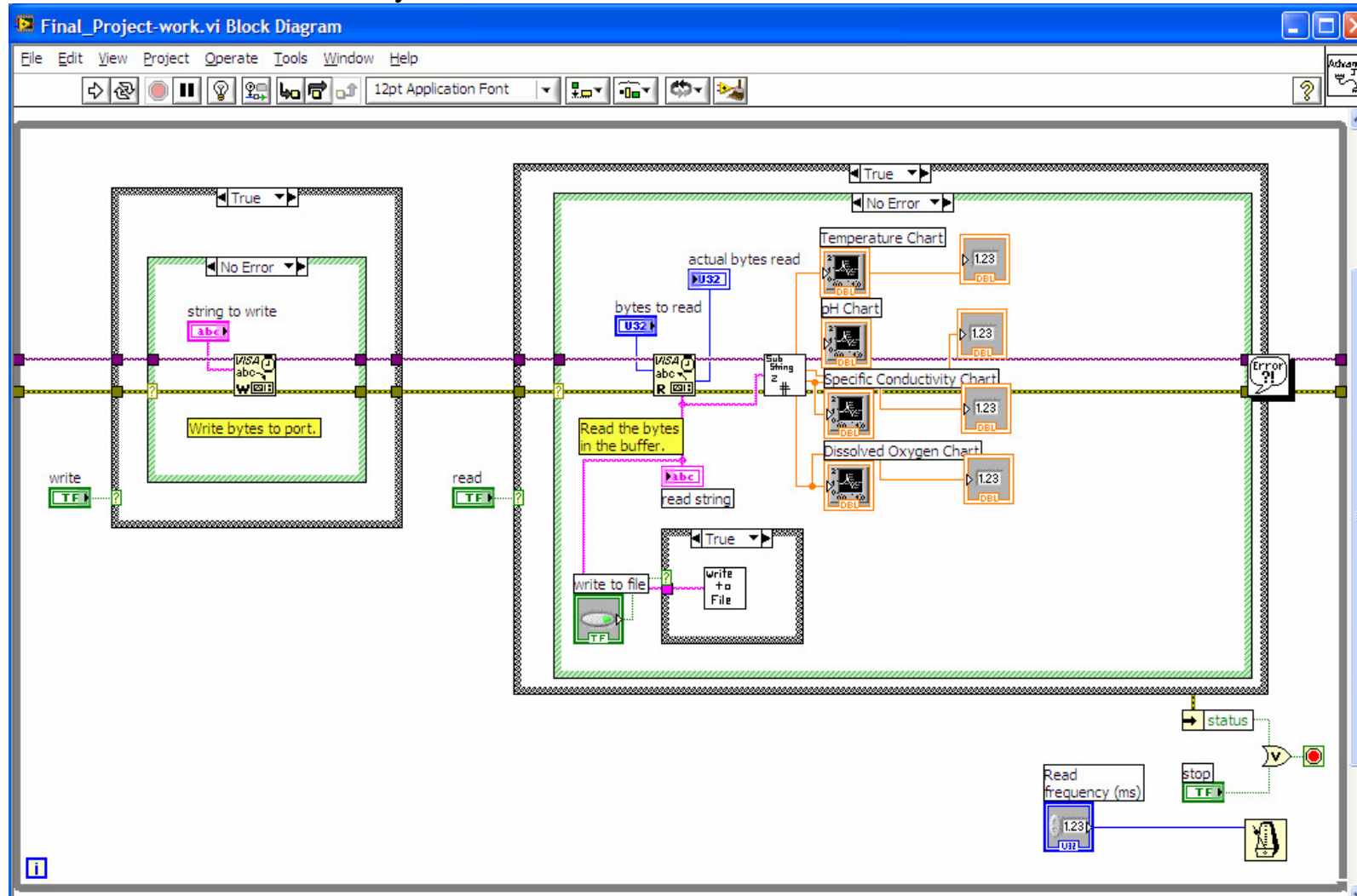

$<$ 
Figure 7: Block diagram for LEWAS phase $1 \mathrm{VI}^{10}$.

The second phase of LEWAS, implemented in summer '09, employs an industrial computer (compactRIO) as server which can run remotely and continuously without user intervention. It is equipped with three modules for serial communications, non-volatile data storage and wireless communications (see Figure 8). The system is operated in an indoor lab setting. The implementation of phase 2 included installation and configuration of two different versions of LabVIEW software on the embedded computer (LabVIEW Real-Time and LabVIEW FPGA) which handles the software aspects of data acquisition and communication with the desktop version installed on a monitoring computer. VIs were developed to run on the Real-Time and FPGA versions of LabVIEW. The functionalities of these VIs are similar to the one demonstrated earlier in phase 1 , however they run on an embedded computer that is more stable and consumes less power than its desktop counterpart (phase 1). These characteristics are essential for the field deployment of the system in phase 3 .

Testing of phase 2 consisted of remote login to the compactRio embedded computer from a remote computer. The only requirement of the remote computer is Internet connection and installation of LabVIEW Run-Time Engine 8.6 (available for free download from the website of National Instruments, the producer of the software). On the server side, an internet connection (campus Internet network was utilized) and a group license for multiple user connection are needed in addition for remote users to interact with the VI and collect water quality information.

The implementation of the phase 3, field deployment in the outdoor lab, started in Fall 2009 and is continuing at the time of this writing. In this phase (see Figure 8), a solar powered and battery backed electrical power supply system, a high gain wireless antenna and I/O module are added to the phase 2 system. A protective enclosure will be used for housing the equipment.

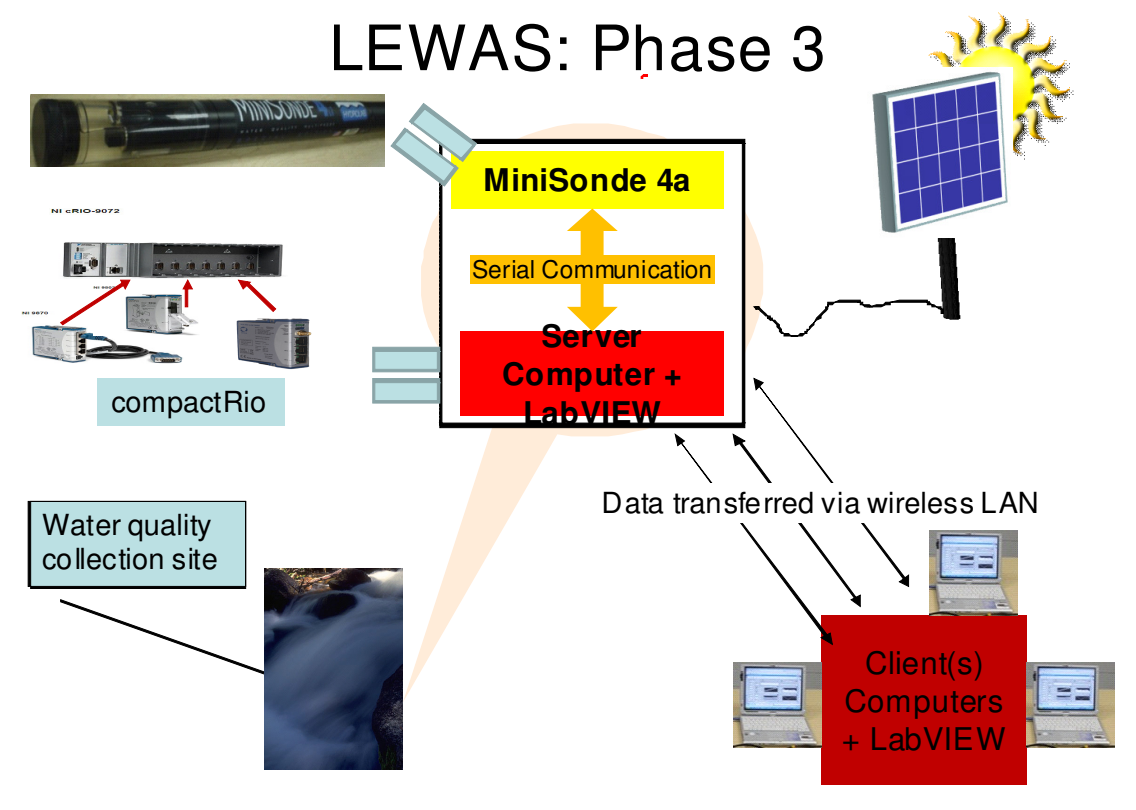


Figure 8: LEWAS - Phase III

Construction of outdoor lab began in Fall 2009; a concrete platform is in place (Figure 10) so that field programming will be comfortably done. Three mounting poles (two wooden and one metal) have been erected and wiring access between the stream and the poles has been provided with underground PVC piping. The enclosure will be mounted on the two wooden poles and the solar panel and antenna on the metal pole. In terms of expandability, the metal pole was chosen to be a standard (2" diameter) size so that most types of equipment can be easily mounted. Also, the enclosure (NexSens AVSS Stainless Steel iSIC Enclosure) is large enough to support more programming equipment if required for future sensors.

A site on the Webb branch of the Stroubles Creek (see figure 10) is chosen to locate this outdoor lab. One important consideration for site selection was the availability of the best wireless signal from the campus wireless network. Figure 10

(http://arcims2.webgis.net/blacksburg/default.asp) shows the site location (indicated by a star) and its proximity to Virginia Tech's main campus.

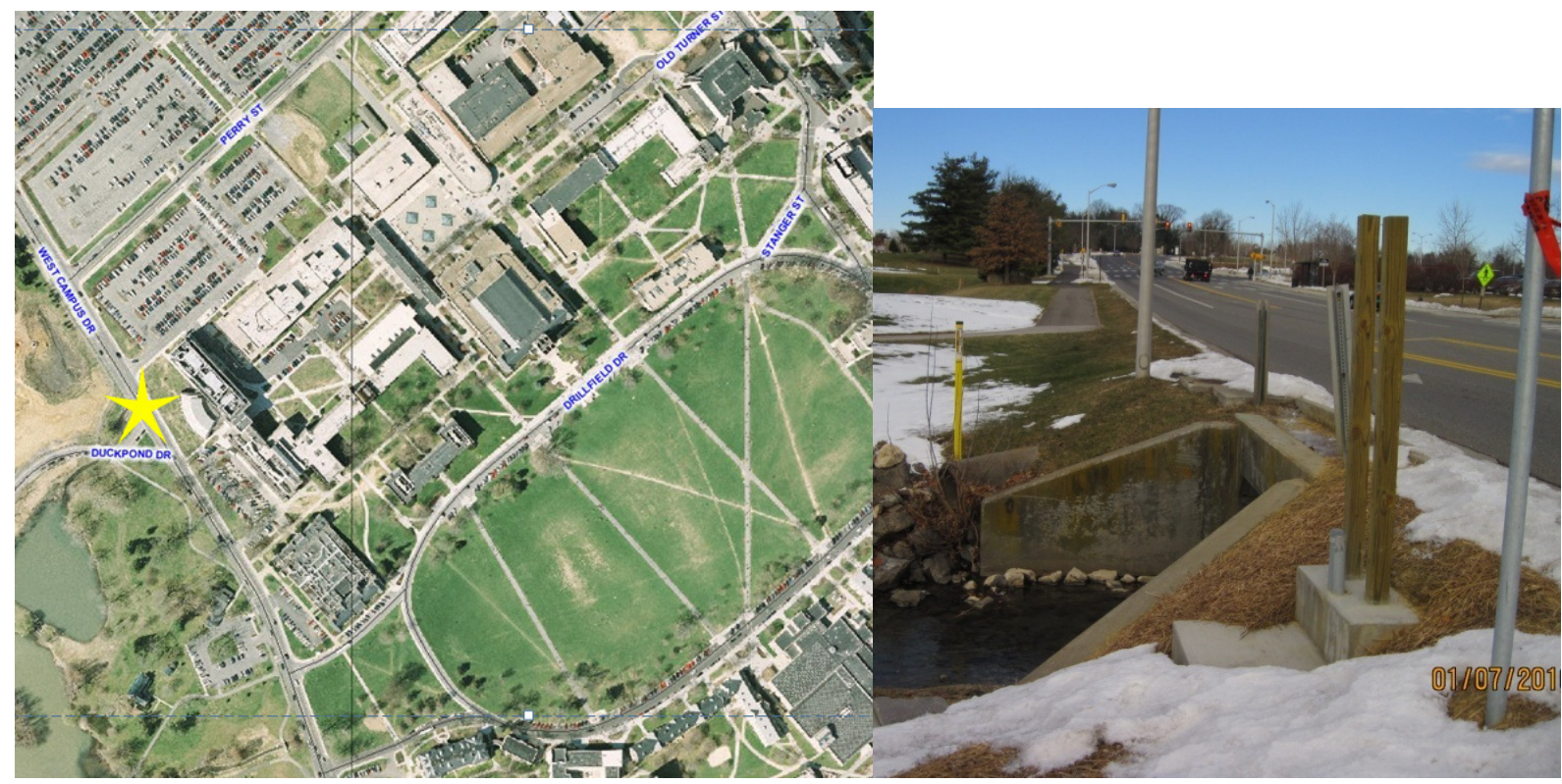

Figure 10: Location of outdoor lab on campus (left) and Outdoor Lab Construction (right)

The detailed design and the layout for the three phase implementation of LEWAS were completed by the first author in Summer ' 08 with feedback from the third author ${ }^{6}$. In addition to the support from the NSF-DLR project, undergraduate fellows from National Science Foundation Research Experiences for Undergraduates (NSF-REU) program held during summer 2008 and summer 2009, contributed to the development of the first two phases of the project under the mentorship of the first author in the interdisciplinary area of watershed sciences and engineering. The second author designed the civil engineering aspects of phase 3 . The third author co-directed the REU program at Virginia Tech. Further details about the NSF-REU program along with implementation details of phase 1 can be found in ${ }^{6}$. 


\section{Demonstration of LEWAS in EngE1024}

Once students completed the "Know your Watershed" worksheet, they were given a demonstration of the LEWAS phase 2 in large lecture sessions. Figure 11 shows display of LEWAS generated water data in classroom along with one of the authors who is providing relevant explanation. Although the complete functionality of the system in phase 2 was tested with limited remote clients before, due to problems with configuring the licensing and webpublishing for the embedded computer a Tablet PC was used instead of the embedded computer. Skype (http://www.skype.com/) software projected the water quality sonde as it measured water quality of a sample in the unmanned LEWAS indoor laboratory. Then, LabVIEW webpublishing was used to show the front-panel of the VI used to collect water quality data (figure 6) as it was updated in real-time. The purpose of the demonstration was to show students an application of the programming language they use in water sustainability. The opportunity was also taken to highlight the research interests of the LEWAS lab and to encourage students to look into this and other research opportunities at Virginia Tech.

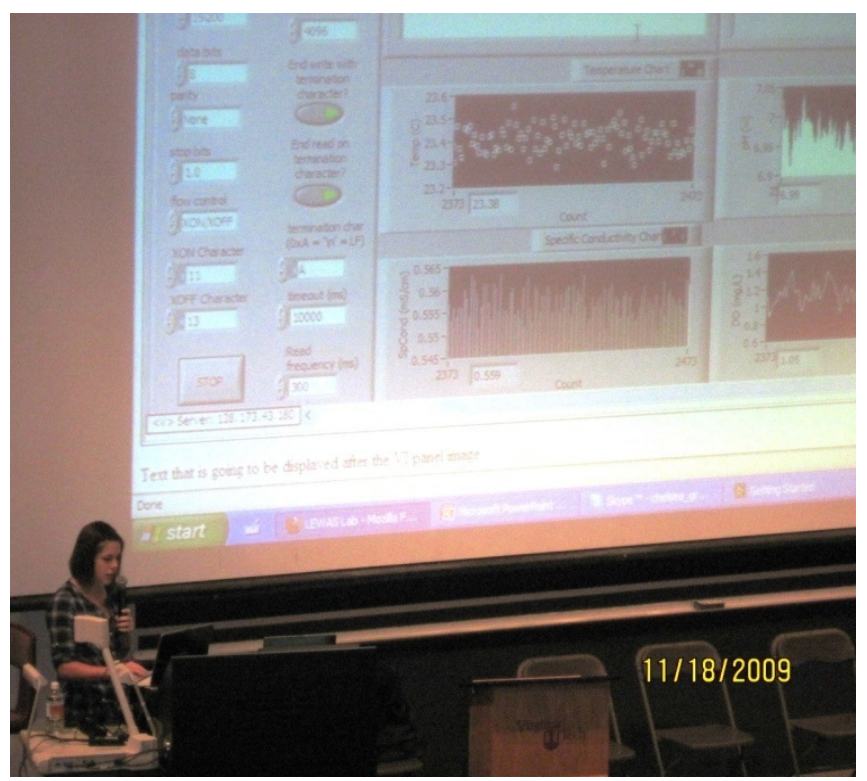

Figure 11: EngE 1024 in-class LEWAS demonstration 


\section{Assessing LabVIEW Curriculum}

\section{Exit Survey Data}

An exit survey, recording students' experiences with EngE 1024, was administered at the end of the course each semester including the five semesters that LabVIEW was introduced (Fall 07, Spring 08, Fall 08, Spring 09 and Fall 09). Three questions in the exit survey measured students' perceptional responses on LabVIEW based activities on a Likert scale. Furthermore, analysis of student responses to the open ended question "What have you learned in this class [EngE 1024] that you think will be useful in your engineering studies?" revealed that a number of students perceived LabVIEW to be useful in their engineering studies. Figure 12 summarizes the semester by semester responses to each question and also show the trends observed over these semesters. (Only Fall semesters are considered due to the much larger number of students taking the course and completing the exit survey.)

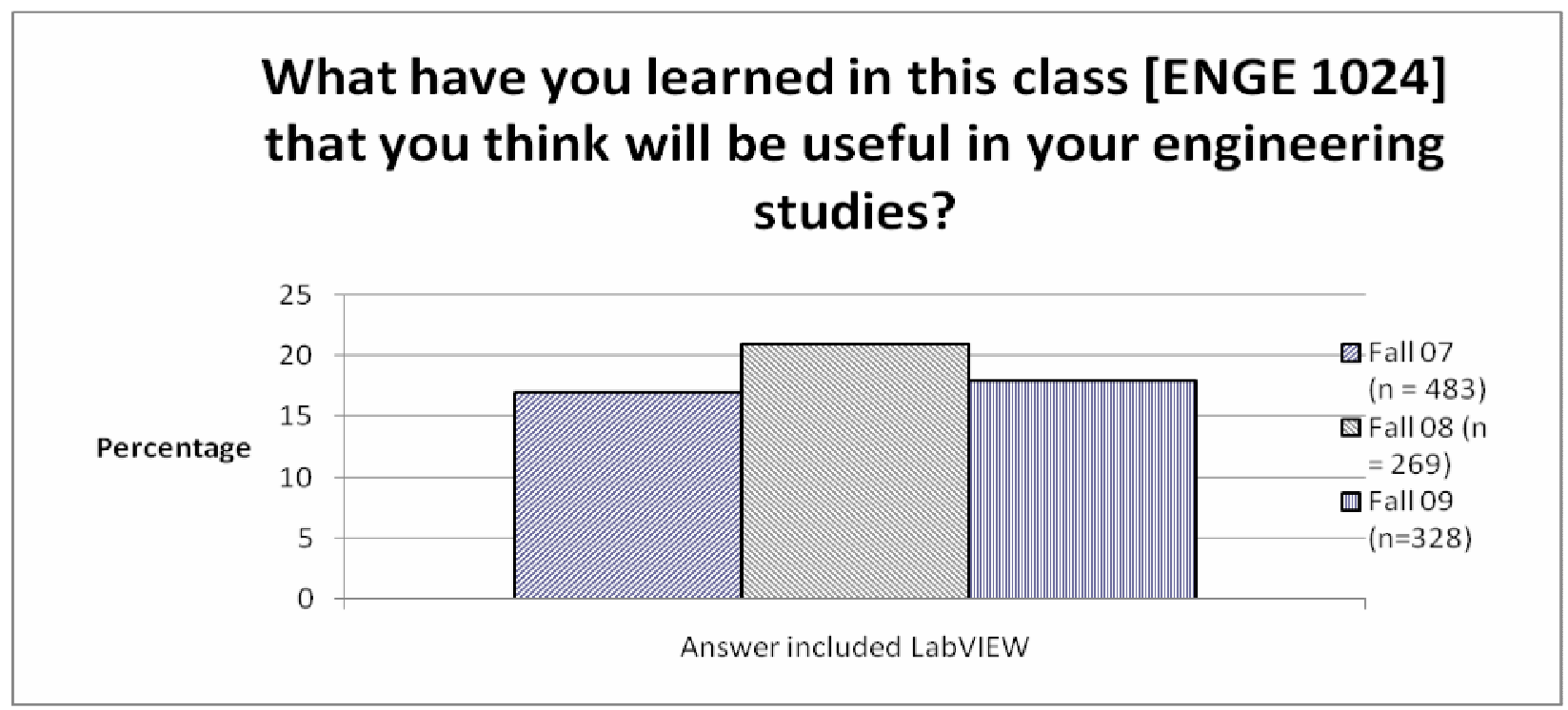

Figure 12: Summary of Exit Survey Data

After running pair-wise $\mathrm{z}$-tests to compare the statistical significance $(\mathrm{p}=0.1)$ of difference in percentage of students in different semesters who included LabVIEW in their responses, it is concluded that the differences between Fall semesters are insignificant and since the introduction of LabVIEW at least one out of six respondents have perceived programming in LabVIEW as one of the subject areas discussed in the course to be useful in their engineering studies. The comparison between Fall 08 and Fall 09 proportions is shown as an example below. 
$n_{1}=483 \quad \hat{\pi}_{1}=0.17$

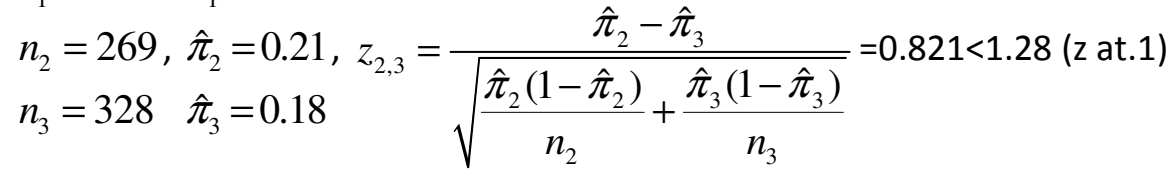

=> Fall 09 proportion is NOT significantly different from Fall 08

In addition, two questions were asked in the exit survey regarding the effectiveness of the "Know your Watershed" worksheet and the in-class monitoring demonstration. The results of these questions are shown in figures 13 and 14.

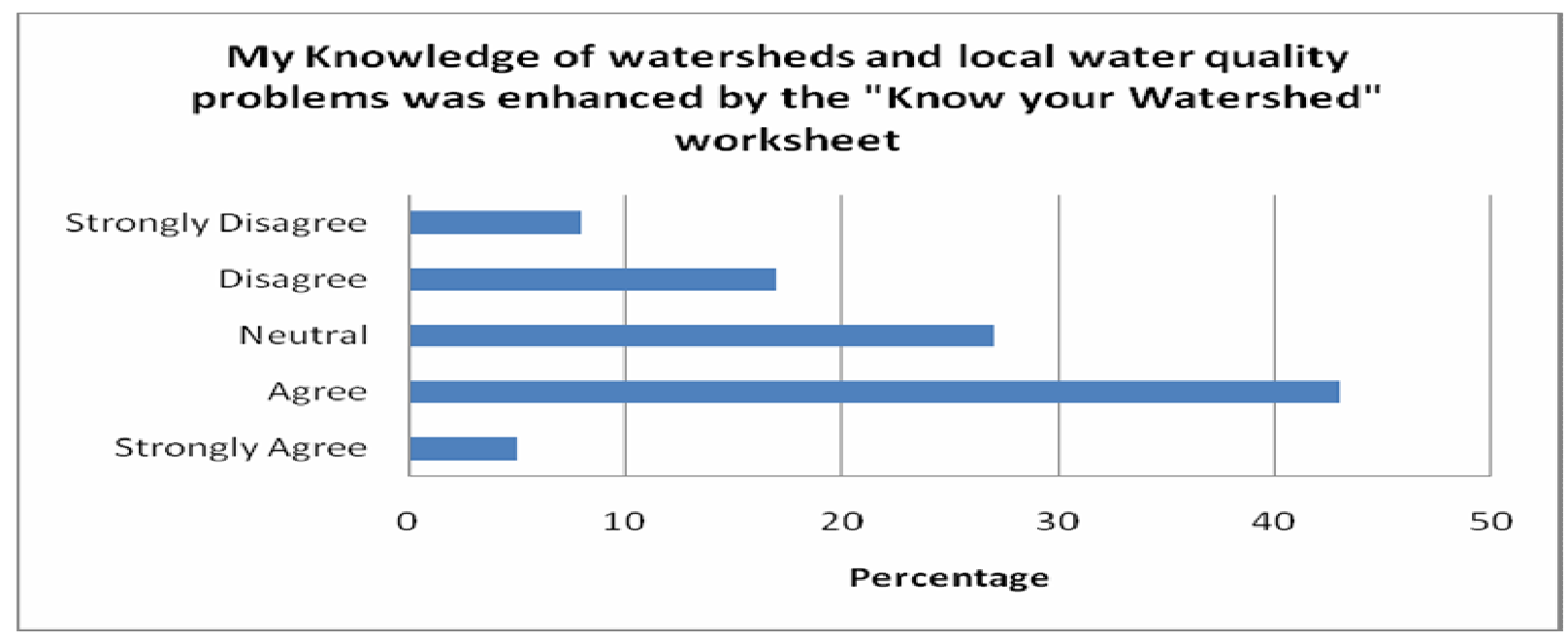

Figure 13: Exit survey question on knowledge of watersshed $(\mathrm{N}=328)$

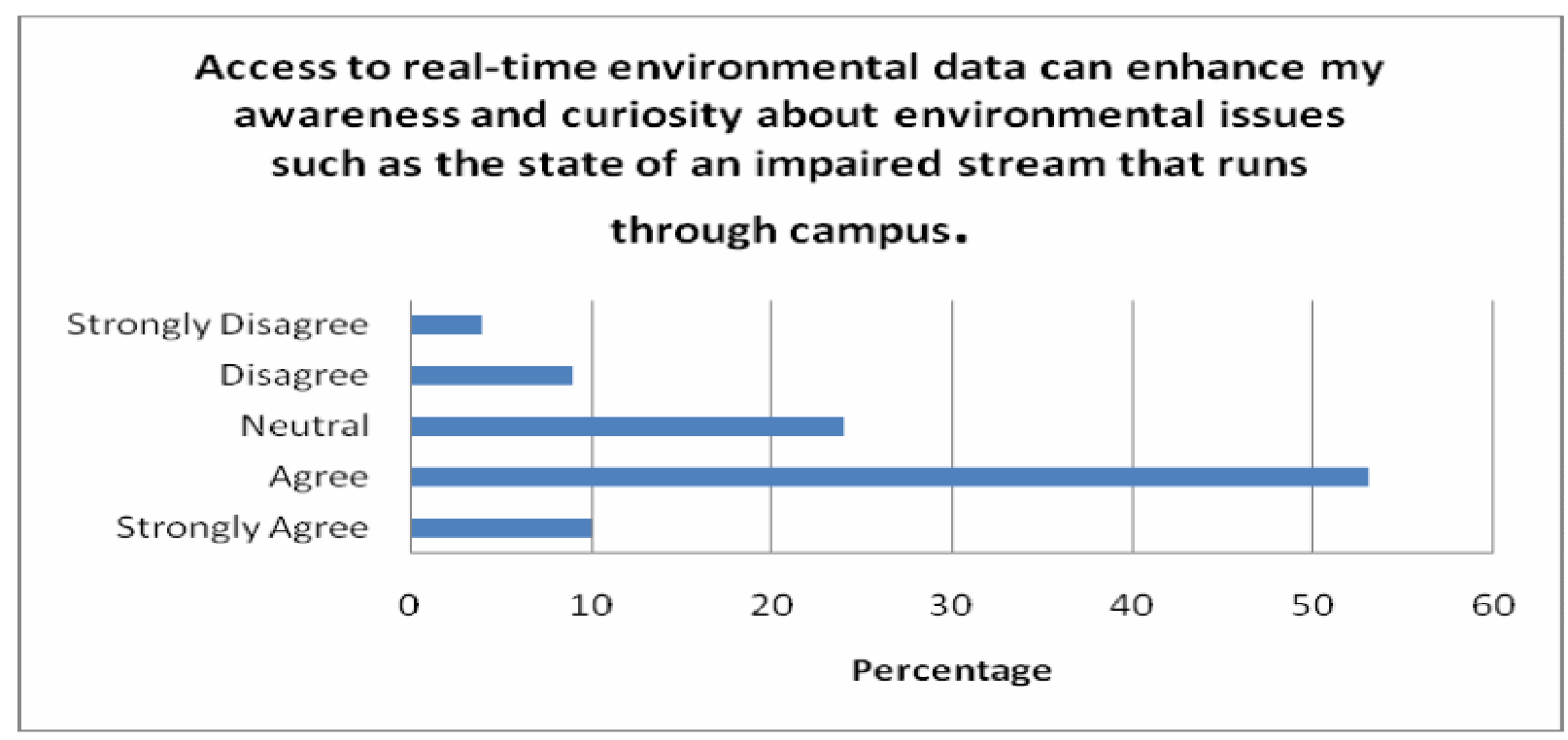


Figure 14: Exit survey question on the role of real-time collection of environmental data on environmental awareness $(\mathrm{N}=327)$

It is seen that students' feedback is very positivegiven that freshmen express interest in a variety of disciplines.

In addition to the exit survey, an in-class survey was conducted in one of the lecture sessions where LEWAS was demonstrated. Student responses were collected using DyKnow ${ }^{13}$ —an interactive software that allows instructors to collect digital feedback directly from students. The following statement was posted for student response: "The week before the break you witnessed demonstration of a LabVIEW enabled system here in class. This system is capable to monitor water data from Stroubles creek in a real-time. You also read a "know your watershed" document. List two things that you learned in above activities."

Eighty-five responses were collected. Two major themes emerged after analyzing these themes. The first was an appreciation for real world LabVIEW applications and its real-time benefit, the second was an understanding of Virginia Tech's watershed and where local water flows. Sixtysix percent students noted a greater appreciation for LabVIEW in real-life applications. One student noted: "I learned the real life application of LabVIEW and that made me interested to learn more". Another student noted: "how it can be used to collect and process data that it collects from real-life sources". The next most prevalent theme was an understanding of the watershed and where water flows from Virginia Tech campus. Some students within this category also noted their appreciation for the effect pollution of their watershed has on the global water system. Of the $35 \%$ that noted watershed knowledge gains, one said "I learned that Stroubles Creek eventually flows into the Gulf of Mexico, it was pretty interesting to see that our pollution here directly affects the ocean." Some other responses outside the two major themes included knowledge gains about specific water quality parameters and an appreciation for Virginia Tech's research interests.

\section{Ongoing work and future plans}

The outdoor LEWAS lab is designed to be expandable so that additional sensors and equipment can be easily deployed. A flow meter has been procured and will be added to the outdoor lab so that the lab can monitor the water flow rate in a real-time. Phosphorus and nitrogen sensors will also be deployed to measure changes in the nutrient content of the stream. The lab also includes a field kit that includes portable $\mathrm{pH}$, dissolved oxygen and temperature sensors and can be used to take field measurements of these parameters at the site of the outdoor lab or elsewhere. This field kit will also be used by researchers to acquire data in other portions of the watershed beyond the measurement capabilities of the LEWAS lab. It is proposed to expand the potential of LEWAS to include analysis of energy conversion from a sustainable source (solar or wind). More details will be included in a future publication. 


\section{Summary}

Authors' experiences with introducing dataflow programming using LabVIEW into a freshman engineering course are discussed. We found that our approach involving gradual integration of the LabVIEW programming concepts into EngE1024 was received well by the students. Exit survey results indicate that approximately one out of six students have listed LabVIEW as one of the topics learned in class that would be useful in their future engineering studies. Development and integration of LEWAS as a logical extension of the LabVIEW are discussed and found useful for enhancing the sustainability component of the course. Analysis of open-ended questions demonstrated the potential of LEWAS ( orLabVIEW programming) in promoting environmental sustainability. Once the outdoor part of LEWAS is completed, students will be able to learn about environmental sustainability using an on-campus stream which is impaired per EPA classification. Additionally, students will see real life application of dataflow programming in acquiring, transmitting and analyzing the data.

\section{Acknowledgement}

The authors would like to acknowledge the support of the EngE1024 faculty and workshop instructors for their help in integrating LabVIEW into the curriculum. We would also like to sincerely acknowledge the funding support provided by the National Science Foundation (DLR Grants 0431779 and 0649070).

\section{References}

1. Lohani, V.K., Sanders, M., Wildman, T., Connor, J., Mallikarjunan, K., Dillaha, T., Muffo, J., Knott, T.W., Lo, J., Loganathan, G.V., Adel, G., Wolfe, M.L., Goff, R., Gregg, M., Chang, M., Agblevor, F., Vaughan, D., Cundiff, J., Fox, E., Griffin, H., and Magliaro, S., 2005. "From BEEVT to DLR: NSF Supported Engineering Education Projects at Virginia Tech," Proc. 2005 Annual Meeting and Conference of the American Society for Engineering Education, Portland, Oregon, June 12-15, 2005.

2. Mullin, J., Jinsoo, K., Lohani, V. K., and Lo, J. (2007). Sustainable Energy Design Projects for Engineering Freshman. Proceedings of the 2007 ASEE Annual Conference and Exposition, Honolulu, HI, June 24-27, 2007.

3. Lohani, V.K., Kachroo, P., Chandrachood, S., Zephirin, T. Loganathan, G.V., \& Lo, J.L. (2006). Mechatronics Experiment in a Freshman Year Course. Proceedings of the 2006 International Conference on Engineering Education (iCEE06), Puerto Rico, July 23-28, 2006, 5 pages.

4. Castles, R., Zephirin, T., Lohani, V. K., and Kachroo, P., Analysis of Freshman Students' Experiences in a Mechatronics Hands-on Workshop in a Large Engineering Program, IEEE Transactions on Education (in review).

5. Lo, J.L., Lohani, V.K. \& Griffin, Jr., O.H. (2006). Full Implementation of a New Format for Freshmen Engineering Course. Proceedings of the 2006 ASEE Annual Conference and Exposition, Chicago, IL, June 18-21, 2006, 15 pages. 
6. Lohani, V. K., Delgoshaei P. \& Green, C (2009). Integrating LabVIEW and Real-Time Monitoring into Engineering Instruction Proceedings of the 2009 ASEE Annual Conference and Exposition, Austin, TX, June 14-17, 2009, 18 pages

7. http://www.ni.com/labview/whatis/applications.htm

8. Gronwald, F., Kenny, J., Adams, E., Delgoshaei, P., Younos, T. and Lohani, V. K. "Water Quality Assessment of a Mixed Land Use Watershed”, 2008 NSF REU Proceedings of Research Research Opportunities in interdisciplinary Watershed Sciences and Engineering

9. Tomales Bay Watershed Council, Tomales Bay Watershed Water Quality Monitoring Plan (2003)

10. Kenny, J., Delgoshaei, P., Gronwald, F., Lohani, V. K. and Younos, T. "Integration of LabVIEW into Stroubles Creek Watershed Assessment”, 2008 NSF REU Proceedings of Research Research Opportunities in interdisciplinary Watershed Sciences and Engineering

11. Glasgow, H., Burkholder J.M., Reed, R.E., Lewitus, A.J., Kleinman, J.E. "Real-time remote monitoring of water quality: a review of current applications, and advancements in sensor, telemetry, and computing technologies”, Journal of Experimental Marine Biology and Ecology, 300 (2004) 409- 448

12. Gagnon, B., Marcoux, G., Leduc, R., Pouet, M.F., Thomas, O. “Emerging tools and sustainability of water-quality monitoring", Trends in Analytical Chemistry, Vol. 26, No. 4, 2007

13. www.dyknow.com

14. Castles, R., Lohani, V. K., Kachroo, P. “Utilizing Hands-on Learning to Facilitate Progression through Bloom's Taxonomy within the First Semester" Proceedings of Frontiers in Education Conference (FIE 2009), San Antonio, TX, 10/18-21/2009 